\title{
NARRATIVA E LEITURA: DA EXPERIÊNCIA ÀS LETRAS
}

\author{
Luana Ferraz ${ }^{1}$ \\ Fabiano de Oliveira Moraes ${ }^{2}$
}

\section{RESUMO}

$\mathrm{Na}$ sociedade contemporânea, a morte se apresenta como o trágico destino da experiência. A urgência da informação, o imperativo do julgamento, a velocidade e o excesso de atividade tornam a possibilidade de que algo nos aconteça, ou de que algo nos toque, cada vez mais remota. Desse modo, espera-se, desde Benjamin (1979), que a narrativa tradicional, profundamente atrelada à experiência, tenha o mesmo fim. Entretanto, a vida tem seus artifícios e sempre encontra meios de se dizer. Mesmo no cenário atual, diferentes leituras do mundo, 'histórias vividas' inscrevem-se (e escrevem-se) no texto escrito do narrador contemporâneo. Assim, as narrativas, dinâmicas, escapando à ordem do necessário e/ou do real sobrevivem para serem lidas e recontadas. A fim de ilustrar a permanência da tradicionalidade na figura do narrador contemporâneo tomamos um trecho do texto de incontestável literariedade "Mitos brasileiros de origem: a arte de contar histórias e a tradição indígena", de Francisco Gregório Filho. Nesse texto, o autor percorre os tempos de sua história familiar, apresentando os momentos que, atualizados e ressignificados, constroem sua identidade como narrador. Interessa-nos observar como o narrador tradicional contemporâneo recolhe sua história na experiência, tornando-a 'escrevível', e como a história pode transformar-se novamente em experiência para os/nos leitores. Nesse percurso, trilhamos as veredas da memória, da identidade e da multiplicidade. Iluminam nosso caminho as palavras de Larrosa (2002), Delgado (2006), Yunes (2003a, 2003b, 2012), Bosi (1987), entre outros.

Palavras-chave: Narrativa. Experiência. Leitura. 


\title{
NARRATIVE AND READING: FROM EXPERIENCE TO LETTERS
}

\begin{abstract}
In contemporary society, death is presented as the tragic fate of experience. The urgency of information, the imperative of judgment, the speed and excess of activity make the possibility of something happening to us, or of something touching us, increasingly remote. So it is expected, as of Benjamin (1979), that the traditional narrative, deeply tied to experience, have the same end. However, life has its tricks and always finds ways of proclaiming itself. Even in the present day scenario of different world interpretations, "stories experienced in life" inscribe themselves (and are written) in the written text of the contemporary narrator. Thus, narratives, dynamic, escaping the order of the necessary and / or real, survive to be read and retold. To illustrate the persistence of traditionalism in the figure of the contemporary narrator, take a snippet of text from the incontestably literary work "Brazilian origin myths: the art of storytelling and indigenous tradition, " by Francisco Gregório Filho. In this text, the author runs through the ages of his familiar history, presenting those moments which, updated and reinterpreted, construct his identity as narrator. We are interested in observing how the traditional contemporary narrator brings his story together out of experience, making it writable, and how the story can be transformed again into experience for and in readers. Along the way, we tread the paths of memory, identity, and multiplicity. The words of Larrosa (2002), Delgado (2006), Yunes (2003a, 2003b, 2012), Bosi (1987), among others, illuminate our path.
\end{abstract}

Keywords: Narrative. Experience. Reading.

\section{NARRAR A DOR}

Minha avó apareceu de barriga. Barriguda. Kaxinawá minha avó. Nascida e criada na bacia hidrográfica do Alto Juruá, região ocidental da Amazônia, fronteira do Brasil com o Peru.

Quando moça, minha avó foi convidada para morar com uma família branca portuguesa e católica em Rio Branco, capital do estado do Acre. A avó foi estudar. Formou-se professora. Encontrou meu avô. Descendente de holandeses que chegaram ao Brasil no século XVIII pelo 
nordeste brasileiro e se espalharam pelas diversas regiões do país. Protestante meu avô. Tempos depois, minha avó apareceu de barriga.

Barriguda, a avó punha uma bacia com água, molhava as mãos e acariciava a barriga. Molhava as mãos e acariciava o barrigão e cantava:

Vou me banhar

Numa água tão cristalina

Em água tão bela e fina

Que desce lá para a maré

Maré, maré...

Vou me banhar

Nas águas do catolé.

Cantava a avó por horas sem-fim, sempre com as mãos molhadas e acariciando o "buchão". Entoava a avó com a voz terna e melodiosa.

Um dia, o avô perguntou-Ihe:

- Maria (nome branco de minha avó, chamado pela família portuguesa católica) para que essas mãos molhadas?

- Ah... Pedro (nome de meu avô), é para o bebê nascer com o coração molhadinho, ensopadinho, para o exercício da tolerância, para a melhor convivência com o outro, com o diferente.

Meu avô deu com os ombros e a mulher continuou a alisar o barrigão e a entoar aquela cantiga docemente.

Em outra ocasião a "buchuda" suspirou fundo dizendo:

- Se nascer menino, vai se chamar Francisco.

Francisco de fé, esperança, influência da família branca (portuguesa) e católica. Francisco de homenagem a São Francisco de Assis, santo católico. Nascesse em 4 de outubro ou não, seria Francisco.

Nascesse menina se chamaria Maria, Esther, Júlia ou Rita. Se menino: Francisco. O homempai ponderou, argumentou, mas... na tradição, as mulheres decidiam, os homens consentiam.

Nasceu... Francisco. Francisco de fé, crença, esperança. Gregório de sobrenome, referência do núcleo familiar. Gregório de reunião das diferentes culturas, Gregório.

A mulher-mãe observava que as pessoas da cidade tinham o costume de grafarem em seus estabelecimentos comerciais seus nomes: Padaria do Pão Bom do Senhor José Augusto da Silva; Farmácia Saúde da Senhora Maria da Silva; Consultório Médico da Senhora Emanuele da Silva; Escritório de Contabilidade do Senhor Jorge da Silva e tantos outros. Então inaugurou na família a referência comunitária: Da Silva. Francisco Gregório da Silva, meu pai, foi para o mundo e encontrou minha mãe, cabocla, negra, descendente dos africanos que chegaram às Américas nos navios negreiros e se misturaram aos índios. Heliete, mulher cabocla e espírita, professora também. Conhecera meu pai e logo depois apareceu grávida, barriguda.

Então minha avó colocava próximo à mulher uma bacia com água e juntas molhavam o barrigão. Com as mãos molhadas, ternas, suavemente entoavam a cantiga, alisando o embrião.

Certa vez minha mãe suspirou e disse:

- Se nascer menino, vai ganhar o nome do pai, Francisco.

Meu pai ponderou, argumentou, mas... na tradição, as mulheres decidiam, os homens consentiam. Nascesse menino, Francisco de fé, "esperanção".

Nasceu, Francisco de homenagem; Gregório de gregário; da Silva, comunitário; Filho, do amor. Francisco Gregório da Silva Filho sou eu. (GREGÓRIO FILHO, 2012, p. 218-220).

\section{SOBRE A MORTE E A VIDA DA EXPERIÊNCIA E DA NARRATIVA} TRADICIONAL

A arte de narrar se distancia de nós e, a cada dia, se aproxima do fim. É o que, com certa melancolia, nos anuncia Walter Benjamin em "O narrador" (1979). Nesse ensaio, em que discute os traços remanescentes do narrador tradicional na obra de 
Nicolai Leskow, Benjamin observa que a crescente pobreza de experiências conduz à agonia da narrativa baseada na 'história vivida'.

Para o autor, um longo processo histórico, marcado pelo advento do romance, que induzia à escrita e à leitura solitária, e pelo desenvolvimento da imprensa, que disseminava a informação admissível e verificável, promovia uma separação ainda em curso e, aparentemente irremediável, entre o narrador e a vida. Não pretendemos (e, mesmo, não poderíamos) discordar de Benjamin. De fato, ainda hoje, o sujeito, dito pós-moderno, está esquecido do vivido, e isso é sinal de que a experiência continua em crise.

Jorge Larrosa (2002) aponta-nos algumas causas da rarefação da experiência na contemporaneidade. Para o pesquisador, esse fenômeno pode ser atribuído, prioritariamente, a quatro fatores, sejam eles, o excesso de informação, o excesso de opinião, a falta de tempo e o excesso de trabalho.

Dizem-nos que vivemos na 'sociedade da informação', na famosa 'aldeia global'. Expostos permanentemente aos meios de comunicação de massa, tornamonos sujeitos bem informados. Na verdade, sujeitos obcecados pela informação, pelas novidades que podemos acessar a cada minuto. No entanto, o mérito da novidade é, exatamente, ser 'nova', e, também por isso, as informações que volumosamente nos chegam não têm tempo de deixar rastro. Sabemos muitas coisas, mas nada efetivamente nos toca, nada nos acontece. Nesse sentido, Larrosa (2002, p. 21) afirma que "a informação não é experiência. E mais, a informação não deixa lugar para a experiência, ela é quase o contrário da experiência, quase uma antiexperiência".

Não basta, porém, que nos mantenhamos informados. Uma vez que quase tudo o que acontece é revertido em proveito da informação, como já indicava-nos Benjamin (1979), é-nos também exigido ter opinião sobre quase tudo. Precisamos apresentar, quase automaticamente, reações subjetivas de concordância ou discordância às informações objetivas que nos são impingidas, sob pena de (se assim não o fizermos) sermos considerados 'alienados', isto é, desinteressados dos acontecimentos do mundo.

Ora, a experiência também pode ser um exercício de alienação, se esta palavra for tomada em sentido 'mais nobre'. Experimentamos efetivamente quando nos permitimos estar alheios, isto é, 'fora de nós mesmos', fora de nossos lugares próprios, de nossos sistemas pré-estabelecidos e observáveis, quando nos 
permitimos ser surpreendidos. Dessa forma, a opinião automática dada em resposta a cada informação inviabiliza a experiência. Opinião e informação caminham, pois, lado a lado, formando a base da imprensa que, de acordo com Benjamin (1979) e Larrosa (2002), constitui o grande dispositivo de destruição da experiência.

A falta de tempo, intrinsecamente relacionada aos dois fenômenos anteriormente expostos, é o terceiro fator exterminador da experiência apontado por Larrosa (2002). Em nosso tempo tecnológico, somos sujeitos ligados por fibras óticas. Tudo acontece 'ao mesmo tempo agora' e, em um mundo tão veloz, nos tornamos, frequentemente, ávidos por estímulos instantâneos e fragmentados. Por corrermos cada vez mais e, ainda assim, termos cada vez menos tempo, faltam-nos o silêncio e a memória. Falta-nos a vivência da temporalidade que possibilita a experiência.

Chegamos, enfim, ao excesso de trabalho. Para Larrosa (2002), o homem contemporâneo é um sujeito hiperativo, que trabalha incessantemente para adequar o mundo a seu saber, a seu poder e a sua vontade. O imperativo da ação, cultivado pela sociedade contemporânea, faz com que o sujeito permaneça sempre mobilizado, perguntando-se sobre o que pode fazer. Considerando-se capaz de realizar, de controlar e de produzir coisas de forma ininterrupta, o sujeito contemporâneo torna-se incapaz de experimentar. É um sujeito ativo e seguro demais para ser tomado pela experiência.

Pois bem. Tendo em vista a rarefação da experiência na sociedade contemporânea, poderíamos simplesmente aceitar que a narrativa baseada na 'história vivida', invariavelmente produzida pela (ou na) experiência, goza de seus últimos dias. Nessa perspectiva, somente nos restaria crer que a vida não é mais uma história a ser contada. Entretanto, isso não é definitivo.

De fato, estamos relativamente afastados do mundo que nos era dado a ler e a contar. Os textos, antes vívidos, apresentam-se hoje, muitas vezes, como relatos irreconhecíveis e enigmáticos que, organizados sobre diferentes suportes, nos impõem uma legibilidade única (YUNES, 2003a).

Contudo, a arte narrativa resiste e, como lugar de criatividade, se reinventa na figura do 'narrador tradicional contemporâneo', que agrega as "histórias criadas e recriadas [...] através da narração de sua experiência e de sua memória" (BEDRAN, 2011, p. 61), à pesquisa e à leitura ${ }^{3}$. Cremos, portanto, que a vida ainda se inscreve astuciosamente no texto do narrador contemporâneo, e que, nesse contexto, a 
efêmera experiência de leitura do mundo, se deixa, às vezes, prender por uma "escrita", tal como nos lembra Yunes (2003b).

Sendo assim, resgataremos a partir de agora o texto que apresentamos no início deste trabalho. Trata-se de um trecho do texto "Mitos brasileiros de origem: a arte de contar histórias e a tradição indígena", de Francisco Gregório Filho, no qual o autor percorre os tempos de sua história familiar com a intenção de apresentar as muitas influências que permeiam o seu narrar. A partir dele, procuramos compreender como o narrador tradicional contemporâneo recolhe sua história na experiência, tornando-a "escrevível" (YUNES, 2003b, p. 50) ${ }^{4}$, e como essa mesma história pode transformar-se novamente em experiência para os/nos leitores.

\section{UMA LEITURA DE FRANCISCO GREGÓRIO FILHO: MEMÓRIA, IDENTIDADE E MULTIPLICIDADE}

Como vimos afirmando, é na vida, e, frequentemente, nas experiências passadas, que a narrativa encontra sua principal fonte. Ao narrar, fazemos constantes referências ao passado, buscamos lembranças, projetamos imagens de acontecimentos supostamente esquecidos. Podemos, assim, reconhecer que as narrativas orais ou escritas constituem um gênero dinâmico, pleno de dimensão temporal, e, portanto, estreitamente ligado à memória.

Lemos em Delgado (2006, p. 38) que a memória "[...] como forma de conhecimento e como experiência, é um caminho possível para que sujeitos percorram os tempos de sua vida". É, portanto, impossível não pensá-la em sua dimensão individual. Sendo assim, concebemos a biografia, o registro de recordações de uma 'história já vivida', como lugar da memória. Por meio do relato biográfico, o indivíduo resgata suas experiências passadas e, traduzindo-as em palavras, reatualiza-as, fazendo-as presentes e, de certa forma, eternas.

Francisco Gregório Filho é um narrador tradicional contemporâneo, e como tal, é um homem memorioso, capaz de transportar as astúcias da história vivida à história narrada. Suas palavras nos conduzem a seu nascimento, no Estado do Acre, na Amazônia brasileira; à escolha de seu nome, Francisco Gregório da Silva Filho; às suas origens. A vida, pessoal, é registrada na escrita e, talvez por isso, a presença de Gregório no texto em que se propõe a discutir o poder da palavra do narrador se manifeste de forma tão imediata, quase física. Talvez escrever, nesse 
caso, seja "[...] "se mostrar", se expor, fazer aparecer o seu próprio rosto perto do outro", tal como nos sugere Foucault (2010, p. 156) para os relatos íntimos das cartas pessoais. Aí está, pois, Gregório, dialogando conosco, oferecendo-se a nossa observação e, ao mesmo tempo, lançando-nos familiarmente o seu olhar.

A leitura do relato de Francisco Gregório Filho, que se inicia bem antes do seu nascimento, nos impele, contudo, a pensar a potencialidade da memória e, por conseguinte, da narrativa, para além do tempo da vida individual e das experiências estritamente pessoais. Os relatos da vida vivida que antecede seu nascimento, concepções de palavras em gestação como afirma o próprio Gregório Filho (2012), narrativas repletas de ritmos grávidos de sentido sobre o mundo, a ele foram narrados certamente pelos mais velhos. As crianças de seu relato, ainda na barriga de suas mães, parecem ter tomado "a iniciativa de inaugurar o encontro narrativo: "Conta para mim a sua história, quero ouvi-la!"” (GIRARDELLO, 2012, p. 56), como a criança do conto hindu Uma história em busca de quem a escute, registrado por Ramanujan (1991) e recontado por Gilka Girardello (2012). Gregório Filho, ao narrar a dor de sua infância, de sua memória, de seus ancestrais, respalda em sua narrativa repleta de literariedade as palavras da autora:

\begin{abstract}
Quando crianças e pessoas com longa experiência de vida conseguem se encontrar de fato na clareira de sentido inaugurada por uma narrativa compartilhada, o que ocorre não é uma lição ministrada por quem sabe a quem não sabe, mas um diálogo do qual ambos são autores, no qual ambos fazem perguntas e esboçam respostas sobre os mistérios que veem na vida, a partir do lugar único no tempo humano que se encontram, o presente (GIRARDELLO, 2012, p. 56-57).
\end{abstract}

Desde a antiguidade, a narrativa configura-se como forma de materializar o "[...] esforço das coletividades para não se perderem no esquecimento e no eterno presente" (DELGADO, 2006, p. 40). Conta a mitologia grega que a deusa da memória e musa da poesia épica, Mnemosyne, concedia aos poetas e adivinhos "o poder de voltar ao passado e lembrá-lo para a coletividade" (CHAUÍ, 2000, p. 159). Narrar é, portanto, de certa forma, uma busca pela preservação da origem, bem como uma possibilidade de autorreconhecimento no conjunto plural das organizações sociais.

Nesse sentido, Ecléa Bosi (1987, p. 18), baseada em Maurice Halbwalchs, diznos que "a memória da pessoa está amarrada à memória do grupo; esta última à esfera maior da tradição, que é a memória coletiva de cada sociedade"; ao que 
podemos acrescentar as palavras de Todorov (1999, p. 114): "[...] quem diz memória coletiva diz também identidade coletiva".

Sim, somos todos diferentes! A leitura de um texto, permeado por experiências plurais, (étnicas, regionais, nacionais, religiosas, culturais), como o de Francisco Gregório Filho, sugere-nos que as identidades não são unívocas, mas múltiplas. Entretanto, é pelo relato de sua história familiar que o narrador registra em palavras a memória da formação do povo brasileiro "branco, índio, negro, mulato, mestiço, vermelho" (GREGÓRIO FILHO, 2012, p. 220), um passado ancestral com o qual todos nos identificamos; o que, afinal nos indica: Sim, somos todos iguais! Desse modo, a tradicionalidade, fenômeno que abarca simultaneamente a identidade e a diferença (BENTES DA SILVA, 2000), é representada na história 'vivida' e narrada por Francisco Gregório Filho.

Certeau, no entanto, adverte-nos de que a narratividade não é um fenômeno que busca simplesmente conformar-se à realidade: "ao contrário, a história narrada cria um espaço de ficção" (2009, p. 142), pois "no saber da experiência não se trata da verdade do que são as coisas, mas do sentido ou do sem-sentido do que nos acontece" (LARROSA, 2002, p. 27).

A matéria-prima da narrativa é a memória viva, a que, segundo Galeano (2002), nasce a cada dia, transformando-se. Assim, quando pensamos a constituição da narrativa tradicional contemporânea, ilustrada pelo texto de Francisco Gregório, a partir de uma concepção ativa e formativa da memória, como a proposta por Halbwachs e retomada por Bosi (1987, p.17), segundo a qual, "na maior parte das vezes, lembrar não é reviver, mas refazer, reconstruir, repensar, com imagens e ideias de hoje, as experiências do passado"; percebemos que o ato de narrar é, de fato, uma prática capaz de "atribuir à memória mais liberdade e mais possibilidades criativas" (CRUZ, 2007).

$\mathrm{Na}$ narrativa de Francisco Gregório Filho, não encontramos simplesmente dados 'históricos', organizados cronologicamente, mas momentos da vida, relidos, ressignificados, que, entrelaçados no texto, constroem a identidade do narrador "aquele que narra a dor. A dor de sentir, degustar e pronunciar" (GREGÓRIO FILHO, 2012, p. 218). O narrador mostra-nos que é, ainda, sujeito da experiência, isto é, sujeito da exposição, da transformação e da paixão (LARROSA, 2002).

Ao dizer quem é, o narrador partilha a vida pela escrita. A narrativa, lida, cria solidariedades, lembra-nos de nós mesmos, dos tempos de infância e das vozes 
amigas. É na leitura (nesse caso, das palavras) que entramos em contato com a experiência do outro, e que, reconstruindo-a, reconstruímo-nos. Nesse processo, (co)movemo-nos, experienciamos pela linguagem o que não pudemos testemunhar, inscrevemo-nos na experiência, imersos no universo das palavras, e regressamos em uma terceira margem (MICHELETTI, 2006).

É provável, assim, que a "interação amorosa" (YUNES, 2003b, p. 52), desenvolvida na leitura de textos 'gregários e comunitários' como os de Francisco Gregório Filho, possa nos tornar mais conscientes da temporalidade, e mais tolerantes diante da multiplicidade. Talvez a narrativa tradicional, que insiste em ter o que dizer na contemporaneidade (YUNES, 2012), possa ainda nos re-humanizar, reaproximando-nos da experiência rarefeita, e, portanto, da vida, contingente e finita, de que nos afastamos por pressa ou por medo.

\section{NOTAS}

${ }^{1}$ Licenciada em Letras-Português e Mestranda em Estudos Linguísticos pela Universidade Federal do Espírito Santo.

${ }^{2}$ Licenciado em Letras-Português, Mestre em Estudos Linguísticos e Doutorando em Educação pela Universidade Federal do Espírito Santo.

${ }^{3}$ No texto "Impressões de uma contadora de histórias - meu encontro com a arte narrativa" (2011), Bia Bedran distingue contadores de histórias tradicionais e contadores contemporâneos. No entanto, neste trabalho, adotamos a denominação 'narrador tradicional contemporâneo', para que as características levantadas pela autora para as duas modalidades de narradores possam ser adequadamente reunidas sob uma designação mais abrangente, tornando nossa exposição mais produtiva.

${ }^{4}$ Termo inspirado em Barthes (1996).

\section{REFERÊNCIAS}

BARTHES, Roland. O prazer do texto. São Paulo: Perspectiva, 1996.

BEDRAN, Bia. Impressões de uma contadora de histórias - meu encontro com a arte narrativa. In: PRIETO, Benita. (Org.). Contadores de histórias: um exercício para muitas vozes. Rio de Janeiro: Prieto Produções Artísticas, 2011. p. 59-65.

BENJAMIN, Walter. O narrador. In: et al. Os pensadores: Benjamin, Habermas, Horkheimer, Adorno. São Paulo: Abril Cultural, 1980. p. 57-74.

BENTES DA SILVA, Anna Christina. A arte de narrar: da constituição das estórias e dos saberes dos narradores da Amazônia paraense. 2000. 313 p. Tese (Doutorado. 
Curso de Linguística do Instituto de Estudos da Linguagem)-Universidade Estadual de Campinas, Campinas, 2000.

BOSI, Ecléa. Memória e sociedade: lembranças de velhos. 2. ed. São Paulo: Editora da Universidade de São Paulo, 1987.

CERTEAU, Michel de. A invenção do cotidiano: 1. Artes de fazer. 16. ed. Petrópolis, RJ: Vozes, 2009.

CHAUÍ, Marilena. Convite à filosofia. 12. ed. São Paulo: Ática, 2000.

CRUZ, Benilton. Memória e invenção. Revista Margens Virtual, Abaetetuba, ano 1, n. 1, nov. 2007. Disponível em: <http://www.ufpa.br/nupe/artigo2.htm>. Acesso em: 12 ago. 2013.

DELGADO, Lucilia de Almeida Neves. História oral: memória, tempo, identidades. Belo Horizonte: Autêntica, 2006.

FOUCAULT, Michel. A escrita de si. In: Ditos e escritos $V$ : ética, sexualidade, política. 2. ed. Rio de Janeiro: Forense Universitária, 2010. p. 144-162.

GALEANO, Eduardo. O livro dos abraços. 9. ed. Porto Alegre, RS: L\&PM, 2002.

GIRARDELLO, Gilka. Na clareira do presente: a arte de contar histórias e o diálogo entre gerações. In: MORAES, F.; GOMES, L. (Orgs.). A arte de encantar: o contador de histórias contemporâneo e seus olhares. São Paulo: Cortez, 2012. p. 41-57.

GREGÓRIO FILHO, Francisco. Mitos brasileiros de origem: a arte de contar histórias e a tradição indígena. In: MORAES, F.; GOMES, L. (Orgs.). A arte de encantar: o contador de histórias contemporâneo e seus olhares. São Paulo: Cortez, 2012. p. 213-225.

LARROSA, Jorge. Notas sobre a experiência e o saber de experiência. Revista Brasileira de Educação, Campinas, n. 19, p. 20-28, jan./ fev. / mar./ abr. 2002.

MICHELETTI, Guaraciaba. A leitura como construção do texto e construção do real. In:__ (Coord.). Leitura e construção do real: o lugar da poesia e da ficção. 4. ed. São Paulo: Cortez, 2006. p. 15-19.

RAMANUJAN, Attipat Krishnaswami. A story in search of an audience. In: Folktales from India: a selection of oral tales from twenty-two languages. New York: Pantheon Books, 1991. p. 26-29.

TODOROV, Tzvetan. O homem desenraizado. Rio de Janeiro: Record, 1999.

YUNES, Eliana. Leitura como experiência. In: ; OSWALD, M. L. (Orgs.). A experiência da leitura. São Paulo: Edições Loyola, 2003a. p. 7-15.

. Leituras, experiência e cidadania. In: YUNES, E.; OSWALD, M. L. (Orgs.). A experiência da leitura. São Paulo: Edições Loyola, 2003b. p. 41-56. 
Contar para ler: A arte de contar histórias e as práticas de leitura. In: MORAES, F.; GOMES, L. (Orgs.). A arte de encantar: o contador de histórias contemporâneo e seus olhares. São Paulo: Cortez, 2012. p. 59-77. 